\title{
Linear Regression Body Surface Area Formula for Infants and Children
}

National Cancer Institute

\section{Source}

National Cancer Institute. Linear Regression Body Surface Area Formula for Infants and

Children. NCI Thesaurus. Code C68651.

The formula to calculate body surface area as described by John D. Current. It is

mathematically defined as: BSA $\left(m^{\wedge} 2\right)=1321+0.3433 \times$ Weight $(g)$ 